\title{
Review of Applications and Environmental Fate of Gold Nanoparticles
}

\author{
Kavitha Palaniappan \\ The University of Newcastle \\ UON Singapore, 6 Temasek Boulevard, \#10-02/03 Suntec Tower 4, Singapore 038986 \\ Kavitha.Palaniappan@newcastle.edu.au
}

\begin{abstract}
The unique properties of nanomaterials do enable them to contribute significantly to environmental protection; however at the same time, they also have a significant negative impact on the environment as well as on living organisms. Among the existing nanomaterials, gold nanoparticle (GNP) is quickly gaining grounds due to its wide ranging uses in the field of medicine, especially radiation therapy and targeted drug delivery. Apparently, the increased production, application and disposal of GNPs have led to an increased release of nanogold into the environment and there are very few studies that bring out the implications of such release. This study aims to review various applications of GNPs and their fate in the environment.
\end{abstract}

Keywords: Gold Nanoparticles, Biomedical Applications, Environmental Fate, Ecotoxicological Effects.

\section{Introduction}

Nanoparticles are particles that have two or more than two dimensions less than $100 \mathrm{~nm}$. Nanoparticles can be made from organic or inorganic or a combination of both organic and inorganic materials. The speciality of these particles is their uniqueness in terms of their physical and chemical properties such as extremely small size, high stability and quantum size effects [1].

Metal nanoparticles are widely used in biomedicine for imaging and therapeutic functions such as for diagnostic purposes, to deliver pharmaceutics and also for targeted drug delivery due to their catalytic, electric, magnetic and optical properties. They can also be used as hyperthermic agents to kill tumour cells by transferring toxic thermal energy as with time, metallic nanoparticles respond resonantly to the magnetic field [2].

Among the metal nanoparticles, gold nanoparticles (GNPs) stand out substantially due to their unique optical and chemical properties that enable their efficient use in the field of biological sciences [3]. Generally, GNPs possess a large reactive and exposed surface area that enables bioconjugation with molecular probes, be it hydrophobic, hydrophilic, anionic, cationic or any neutral moieties [4].

\section{Applications of Gold Nanoparticles in the field of Medicine}

The prelude to using nanogold in the field of medicine dates back to 1890 when gold salt was proposed as an effective bacteriostatic agent against tuberculosis and subsequently in 1927, gold was also found to be effective against rheumatoid arthritits [5].

GNPs exhibit different shapes and sizes. The tuning capability of the GNPs' surface plasmon absorption band over a wide range of absorption region by introducing anisotropy into the GNPs has led to the development of various nanostructures such as nanorods, prisms or triangles, wires, multipodes, stars, tadpoles, etc [6]. Based on their various shapes and sizes, they are extensively used in the field of biomedical sciences. Hollow GNPs in the size range of $25 \mathrm{~nm}$ are used for cancer therapy [7]; gold nanorods of $2.5 \mathrm{~nm}$ are used for drug delivery and photothermal therapy [8]. Gold nanocages are explored extensively in in vivo medical applications [9]. Branched GNPs of about $90 \mathrm{~nm}$ serve as substrates for SERS-based imaging of kidney cells [10]. Triangular GNPs have been found to be highly effective against E.coli and K.pneumonia [11].

The large surface area of GNPs implies that their surface is readily available for modification which in turn facilitates their use as targeting molecules or specific biomarkers [8]. GNP's surface plasmon resonance properties enables their efficient use in tumor and in vivo imaging [12], photo thermal therapy [13] and drug delivery [14]. Their efficiency in targeted drug delivery has further been explored in radiation medicine and GNPs are used as radiation enhancers in 
radiation therapy [7]. Taking their drug delivery capability to a step higher, Tang et al., made GNPs-stabilized capsules using an oil core stabilized by amino acids conjugated with cationic GNPs. These capsules are capable of fusing directly with the cell membrane and have been found to be an efficient protein delivery system either into the cytosol or even more specifically to the nucleus [15]. Gene delivery can also be carried out through GNPs due to their excellent biocompatibility [16]. GNPs are also known to be effective delivery agents for small interfering RNA and DNA-based enzymes [17]. The highly enhanced and tunable optical properties of gold nanorods in both visible and near infrared regions make them suitable for gene delivery, biosensing [3] and for X-ray CT imaging [18]. DNA vaccines have been effectively delivered through GNPs [19].

The extensive surface area of GNPs also provide them with a high drug loading capacity which is made use of in cancer therapy. The monolayers of GNPs enable effective drug loading either through non-covalent interaction or by covalent conjugation [20]. The attraction and binding capacity of GNPs have been found to be strong with small biomolecules like carboxylic acid [21], proteins and enzymes [16], DNA and aminoacids [22]. Another important aspect of GNPs is their ability to disperse uniformly and reach the targeted site along with the blood flow [23]. They have also found to be biocompatible [24] with their overall cytotoxicity within acceptable limits [25].

Another commonly employed technique in cancer treatment is focusing heat on tumours as it has been established in the literature that heat is an effective weapon against tumour cells [26]. However, in the real-life scenario it is quite difficult to concentrate the heat on only the tumour cells and usually in the process many healthy cells also get killed [27]. This problem is overcome by using GNPs which can specifically focus heat only on the tumour cells, leaving the healthy cells untouched [28]. This is achieved by conjugating the GNPs with anti-EGFR, which is basically an antibody for the epidermal growth factor receptor (EGFR), a protein that is usually found only on the surface of tumour cells. This enables the GNP to specifically attach to the tumour cells and concentrate the heat from infrared light to destroy the cancer cells [29]. Another alternative is to directly bind a tumour-killing agent like tumour necrosis factor alpha (TNF) to the GNPs which can in turn deliver and kill the tumour cells [30].

Even though various clinical trials of GNPs ranging from drug carriers to imaging agents have been extensively employed and studied, GNPs' in vivo toxicity studies are very limited and currently in the preliminary stages. It may not be ideal to extrapolate the in vitro toxicity studies to in vivo results as the whole organism is much more complex than a single cell or cell lines [31]. Hence, it is necessary to analyse and research the entire life cycle of the gold nanoparticle within living organisms, including their cytotoxicity, bio-distribution and clearance from the body. Furthermore, even though we can clearly see that GNPs have revolutionized the field of medicine due to their wide spread applications; what about their fate once they are released into the environment, either during the production process or after their use?

\section{Environmental Fate of GNPs}

Generally, nanotoxicity studies have been done on higher organisms that are acceptable to the regulatory agencies for defining their ecotoxicological effects. However, Barrena et al.'s study indicate that such restrictions does not bring out the complete toxicity of nanomaterials in the environment [32]. Their bioluminescent test to evaluate the harmful effects of solvent and suspension of GNP discharged into the surface waters did not present any toxic effects.

Just like how studies on higher organisms may limit our knowledge on toxicity of nanomaterials in the environment, one is also not sure whether effects seen in laboratory experiments can be relevant at the actual environmental exposure levels [33]. It has also been noted that the difficulties of measuring nanoparticles in environmental media pose several uncertainties in terms of their environmental fate and behaviour [34].

Aquatic and terrestrial ecosystems are the major pathways for the entrance of GNPs and for their distribution all throughout the food web [35]. The major sources for these two ecosystems include atmospheric deposition, leaching, direct discharge from domestic and industrial sources and natural run-off [36].

In an aquatic ecosystem, the GNP-specific properties such as its size, shape, state and surface charge [37] and the hydrodynamics of the water body such as presence of natural organic matter [38], $\mathrm{pH}$, ionic strength and composition [39] would determine the behaviour, dissolution, interaction, aggregation, agglomeration, sedimentation and transportation potential of the GNPs.

It was found that the GNPs tend to remain suspended for months together in storm water and freshwater, whereas for a much lesser time (weeks) in ground water and marine ecosystem. However, GNPs are toxic at $<10 \mathrm{mg} / \mathrm{L}$ of seawater compared to their toxicity at $>10 \mathrm{mg} / \mathrm{L}$ in freshwater [40]. This can be attributed to the high ionic strength and the 
presence of divalent cations in the seawater, which accelerates the sedimentation and agglomeration velocities of the GNPs in the marine ecosystem [41].

One study, using mesocosms, exposed the cordgrass Spartina alterniflora, the mudsnail Ilyanassa obsolete, the grass shrimp Palaemonetes pugio, the clam Mercenaria mercenaria, the sheepshead minnow Cyprinodon variegatus and microbial biofilm to gold nanorods for about 12 days. Their objective was to study the bioconcentration, partitioning and the distribution of gold nanorods in the various compartments of the environment. They found that almost about $60 \%$ accumulated in the biofilm whereas 5\% accumulated in clams. Further to that, 25\% of the GNPs was found deposited in the sediments [42].

Dwivedi et al. [43] and Quik et al. [44] have identified that the initial GNP concentration and the natural organic matter content in a terrestrial system are the two main parameters that influence the residential capacity of the GNPs.

One study found that released GNPs tend to accumulate in plant roots and in barley plants, the GNPs permanently decreased their root growth [45]. It is also essential to review studies based on size-dependent mechanisms of GNP uptake as smaller particles of about $3.5 \mathrm{~nm}$ are able to move into the vasculature of the plants from the roots compared to particles of size $18 \mathrm{~nm}$ that remained agglomerated onto the outer surface of the roots. It was also found that the $3.5 \mathrm{~nm}$ GNPs caused leaf necrosis after 14 days of exposure in tobacco plants [46].

Certain studies have also demonstrated the bioavailability and biomagnification of GNPs across different trophic levels [47], [48]. GNP transfer in the terrestrial trophic chain from tobacco (Nicotiana Tabacum L. cv Xanthi) to the tobacco hornworm Manduca sexta was studied and biomagnification was noted [48]. Likewise, GNP transfer and accumulation in the terrestrial trophic chain from the earthworm Eisenia fetida to the bullfrog Rana catesbeina was also studied and noted similar results of biomagnification along with accumulation in liver, kidney, spleen, muscle, stomach and intestines [49].

Renault et al. looked at the localization capability of GNPs, structural disturbances in tissues and genetic expression in algae Scenedesmus subspicatus and in clam Corbicula fluminea. It was found that GNPs can penetrate the branchial and digestive epithelia of C.fluminea and can also lead to modifications of the genetic expression of six genes. The modifications of the genetic expression was due to an increase in metallothioneins which were basically induced by the GNPs [50].

\section{Conclusion}

Thus, one can clearly see from the above studies that GNPs can accumulate in the environment, be it the aquatic ecosystem or the terrestrial ecosystem. Such a behaviour indicates that they must be considered at par with their corresponding metal ionic forms. The literature lacks more intricate toxicity studies pertaining to realistic environmental conditions. Moving forward, it is also essential to study the various factors that may enhance or diminish the toxicity of GNPs in the environment in order to facilitate their safe usage.

\section{References}

[1] D. Kim and S. Jon, "Gold nanoparticles in image-guided cancer therapy," Inorganica Chim. Acta, vol. 393, pp. 154$164,2012$.

[2] N. G. Khlebtsov and L. A. Dykman, "Optical properties and biomedical applications of plasmonic nanoparticles," $J$. Quant. Spectrosc. Radiat. Transf., vol. 111, no. 1, pp. 1-35, 2010.

[3] R. Pal, S. Panigrahi, D. Bhattacharyya, and A. S. Chakraborti, "Characterization of citrate capped gold nanoparticlequercetin complex: Experimental and quantum chemical approach,” J. Mol. Struct., vol. 1046, pp. 153-163, 2013.

[4] A. K. Khan, R. Rashid, G. Murtaza, and A. Zahra, "Gold Nanoparticles: Synthesis and Applications in Drug Delivery," Trop. J. Pharm. Res., vol. 13, no. 7, pp. 1169-1177, 2014.

[5] A. S. Thakor, J. Jokerst, C. Zavaleta, T. F. Massoud, and S. S. Gambhir, "Gold nanoparticles: a revival in precious metal administration to patients," Nano Lett., vol. 11, no. 10, pp. 4029-4036, 2011.

[6] P. Nalawade, T. Mukherjee, and S. Kapoor, "High-yield synthesis of multispiked gold nanoparticles: Characterization and catalytic reactions," Colloids Surf. Physicochem. Eng. Asp., vol. 396, pp. 336-340, 2012.

[7] M. Ganeshkumar, T. P. Sastry, M. Sathish Kumar, M. G. Dinesh, S. Kannappan, and L. Suguna, "Sun light mediated synthesis of gold nanoparticles as carrier for 6-mercaptopurine: Preparation, characterization and toxicity studies in zebrafish embryo model," Mater. Res. Bull., vol. 47, no. 9, pp. 2113-2119, 2012. 
[8] Q. Guo, Q. Guo, J. Yuan, and J. Zeng, "Biosynthesis of gold nanoparticles using a kind of flavonol: Dihydromyricetin," Colloids Surf. Physicochem. Eng. Asp., vol. 441, pp. 127-132, 2014.

[9] G. Bisker, D. Yeheskely-Hayon, L. Minai, and D. Yelin, "Controlled release of Rituximab from gold nanoparticles for phototherapy of malignant cells," J. Control. Release Off. J. Control. Release Soc., vol. 162, no. 2, pp. 303-309, 2012.

[10] I. M. M. Paino, V. S. Marangoni, R. de C. S. de Oliveira, L. M. G. Antunes, and V. Zucolotto, "Cyto and genotoxicity of gold nanoparticles in human hepatocellular carcinoma and peripheral blood mononuclear cells," Toxicol. Lett., vol. 215, no. 2, pp. 119-125, 2012.

[11] P. Murawala, A. Tirmale, A. Shiras, and B. L. V. Prasad, "In situ synthesized BSA capped gold nanoparticles: Effective carrier of anticancer drug Methotrexate to MCF-7 breast cancer cells," Mater. Sci. Eng. C, vol. 34, pp. 158-167, 2014.

[12] D. A. Giljohann, D. S. Seferos, W. L. Daniel, M. D. Massich, P. C. Patel, and C. A. Mirkin, "Gold nanoparticles for biology and medicine," Angew. Chem. Int. Ed Engl., vol. 49, no. 19, pp. 3280-3294, 2010.

[13] D. B. Chithrani, M. Dunne, J. Stewart, C. Allen, and D. A. Jaffray, "Cellular uptake and transport of gold nanoparticles incorporated in a liposomal carrier," Nanomedicine Nanotechnol. Biol. Med., vol. 6, no. 1, pp. 161$169,2010$.

[14] M. Amjadi and L. Farzampour, "Fluorescence quenching of fluoroquinolones by gold nanoparticles with different sizes and its analytical application," J. Lumin., vol. 145, pp. 263-268, 2014.

[15] R. Tang et al., "Direct delivery of functional proteins and enzymes to the cytosol using nanoparticle-stabilized nanocapsules," ACS Nano, vol. 7, no. 8, pp. 6667-6673, 2013.

[16] K. Lee, H. Lee, K. H. Bae, and T. G. Park, "Heparin immobilized gold nanoparticles for targeted detection and apoptotic death of metastatic cancer cells," Biomaterials, vol. 31, no. 25, pp. 6530-6536, 2010.

[17] S. Hassan et al., "Evolution and clinical translation of drug delivery nanomaterials," Nano Today, vol. 15, pp. 91106, Aug. 2017.

[18] M. Stobiecka and M. Hepel, "Double-shell gold nanoparticle-based DNA-carriers with poly-L-lysine binding surface," Biomaterials, vol. 32, no. 12, pp. 3312-3321, 2011.

[19] X.-C. Gou, J. Liu, and H.-L. Zhang, "Monitoring human telomere DNA hybridization and G-quadruplex formation using gold nanorods," Anal. Chim. Acta, vol. 668, no. 2, pp. 208-214, 2010.

[20] L. Yu, J.-J. Qiu, H. Cheng, Z.-H. Luo, "Facile preparation of gold nanoparticles using the self-assembled ABC nonamphiphilic fluorosilicone triblock copolymer template," Mater. Chem. Phys., vol. 138, no. 2-3, pp. 780-786, 2013.

[21] S. Deb, H. K. Patra, P. Lahiri, A. K. Dasgupta, K. Chakrabarti, and U. Chaudhuri, "Multistability in platelets and their response to gold nanoparticles," Nanomedicine Nanotechnol. Biol. Med., vol. 7, no. 4, pp. 376-384, 2011.

[22] C. Di Guglielmo, D. R. López, J. De Lapuente, J. M. L. Mallafre, and M. B. Suàrez, "Embryotoxicity of cobalt ferrite and gold nanoparticles: a first in vitro approach," Reprod. Toxicol. Elmsford N, vol. 30, no. 2, pp. 271-276, 2010.

[23] C. Kojima, Y. Umeda, A. Harada, and K. Kono, "Preparation of near-infrared light absorbing gold nanoparticles using polyethylene glycol-attached dendrimers," Colloids Surf. B Biointerfaces, vol. 81, no. 2, pp. 648-651, 2010.

[24] F. K. Alanazi, A. A. Radwan, and I. A. Alsarra, "Biopharmaceutical applications of nanogold," Saudi Pharm. J. SPJ Off. Publ. Saudi Pharm. Soc., vol. 18, no. 4, pp. 179-193, 2010.

[25] M. Benkovicova, K. Vegso, P. Siffalovic, M. Jergel, S. Luby, and E. Majkova, "Preparation of gold nanoparticles for plasmonic applications," Thin Solid Films, vol. 543, pp. 138-141, 2013.

[26] S. Lal, S. E. Clare, and N. J. Halas, "Nanoshell-enabled photothermal cancer therapy: impending clinical impact," Acc. Chem. Res., vol. 41, no. 12, pp. 1842-1851, 2008.

[27] P. K. Jain, X. Huang, I. H. El-Sayed, and M. A. El-Sayed, "Noble metals on the nanoscale: optical and photothermal properties and some applications in imaging, sensing, biology, and medicine," Acc. Chem. Res., vol. 41, no. 12, pp. 1578-1586, 2008.

[28] G. von Maltzahn et al., "Computationally guided photothermal tumor therapy using long-circulating gold nanorod antennas," Cancer Res., vol. 69, no. 9, pp. 3892-3900, 2009.

[29] Georgia Institute of Technology, "Using Gold Nanoparticles to Hit Cancer Where It Hurts," ScienceDaily, 18-Feb2010. [Online]. Available: http://www.news.gatech.edu/2010/02/15/using-gold-nanoparticles-hit-cancer-where-ithurts. [Accessed: 30-Jan-2018]. 
[30] "Nanotechnology in Cancer Treatment," Understandingnano.com. [Online]. Available: http://www.understandingnano.com/cancer-treatment-nanotechnology.html. [Accessed: 30-Jan-2018].

[31] L. Shahidi Bonjar, "Nanogold detoxifying machine' to remove idle nanogold particles from blood stream of cancer patients treated with antibody-nanogold therapeutics," Med. Hypotheses, vol. 80, no. 5, pp. 601-605, May 2013.

[32] R. Barrena, E. Casals, J. Colón, X. Font, A. Sánchez, and V. Puntes, "Evaluation of the ecotoxicity of model nanoparticles," Chemosphere, vol. 75, no. 7, pp. 850-857, 2009.

[33] S. T. Stern and S. E. McNeil, "Nanotechnology safety concerns revisited," Toxicol. Sci. Off. J. Soc. Toxicol., vol. 101, no. 1, pp. 4-21, 2008.

[34] K. Aschberger et al., "Considerations on information needs for nanomaterials in consumer products," Discuss. Label. Report. Scheme Nanomater. Consum. Prod. EU, 2014.

[35] E. Navarro et al., "Environmental behavior and ecotoxicity of engineered nanoparticles to algae, plants, and fungi," Ecotoxicol. Lond. Engl., vol. 17, no. 5, pp. 372-386, 2008.

[36] G. Vale, K. Mehennaoui, S. Cambier, G. Libralato, S. Jomini, and R. F. Domingos, "Manufactured nanoparticles in the aquatic environment-biochemical responses on freshwater organisms: A critical overview," Aquat. Toxicol., vol. 170, pp. 162-174, 2016.

[37] A. A. Keller et al., "Stability and Aggregation of Metal Oxide Nanoparticles in Natural Aqueous Matrices," Environ. Sci. Technol., vol. 44, no. 6, pp. 1962-1967, 2010.

[38] A. R. Petosa, D. P. Jaisi, I. R. Quevedo, M. Elimelech, and N. Tufenkji, "Aggregation and Deposition of Engineered Nanomaterials in Aquatic Environments: Role of Physicochemical Interactions," Environ. Sci. Technol., vol. 44, no. 17, pp. 6532-6549, 2010.

[39] H. Selck, R. D. Handy, T. F. Fernandes, S. J. Klaine, and E. J. Petersen, "Nanomaterials in the aquatic environment: A European Union-United States perspective on the status of ecotoxicity testing, research priorities, and challenges ahead," Environ. Toxicol. Chem., vol. 35, no. 5, pp. 1055-1067, 2016.

[40] K. L. Garner and A. A. Keller, "Emerging patterns for engineered nanomaterials in the environment: a review of fate and toxicity studies," J. Nanoparticle Res., vol. 16, no. 8, Aug. 2014.

[41] K. Aschberger, C. Micheletti, B. Sokull-Klüttgen, and F. M. Christensen, "Analysis of currently available data for characterising the risk of engineered nanomaterials to the environment and human health - Lessons learned from four case studies," Environ. Int., vol. 37, no. 6, pp. 1143-1156, 2011.

[42] J. L. Ferry et al., "Transfer of gold nanoparticles from the water column to the estuarine food web," Nat. Nanotechnol., vol. 4, no. 7, pp. 441-444, 2009.

[43] A. D. Dwivedi, S. P. Dubey, M. Sillanpää, Y.-N. Kwon, C. Lee, and R. S. Varma, "Fate of engineered nanoparticles: Implications in the environment," Coord. Chem. Rev., vol. 287, pp. 64-78, 2015.

[44] J. T. K. Quik, M. C. Stuart, M. Wouterse, W. Peijnenburg, A. J. Hendriks, and D. van de Meent, "Natural colloids are the dominant factor in the sedimentation of nanoparticles," Environ. Toxicol. Chem., vol. 31, no. 5, pp. 1019$1022,2012$.

[45] N. Feichtmeier, P. Walther, and K. Leopold, "Uptake, effects, and regeneration of barley plants exposed to gold nanoparticles," Environ. Sci. Pollut. Res., vol. 22, no. 11, pp. 8549-8558, 2015.

[46] T. Sabo-Attwood et al., "Uptake, distribution and toxicity of gold nanoparticles in tobacco (Nicotiana xanthi) seedlings," Nanotoxicology, vol. 6, no. 4, pp. 353-360, 2012.

[47] J. D. Judy, J. M. Unrine, W. Rao, S. Wirick, and P. M. Bertsch, "Bioavailability of Gold Nanomaterials to Plants: Importance of Particle Size and Surface Coating," Environ. Sci. Technol., vol. 46, no. 15, pp. 8467-8474, Aug. 2012.

[48] J. D. Judy, J. M. Unrine, and P. M. Bertsch, "Evidence for Biomagnification of Gold Nanoparticles within a Terrestrial Food Chain," Environ. Sci. Technol., vol. 45, no. 2, pp. 776-781, 2011.

[49] J. M. Unrine, W. A. Shoults-Wilson, O. Zhurbich, P. M. Bertsch, and O. V. Tsyusko, "Trophic Transfer of Au Nanoparticles from Soil along a Simulated Terrestrial Food Chain.," Environ. Sci. Technol., vol. 46, no. 17, pp. 9753-9760, 2012.

[50] S. Renault, M. Baudrimont, N. Mesmer-Dudons, P. Gonzalez, S. Mornet, and A. Brisson, "Impacts of gold nanoparticle exposure on two freshwater species: a phytoplanktonic alga (Scenedesmus subspicatus) and a benthic bivalve (Corbicula fluminea)," Gold Bull., vol. 41, no. 2, pp. 116-126, 2008. 